\title{
Numerical simulation study on the influence of pulverized coal particle size on boiler combustion characteristics
}

\author{
Zhihai Cheng ${ }^{1}$, Yang $\mathrm{Li}^{1}$ and Zhonghan Zhang ${ }^{1}$ \\ ${ }^{1}$ College of energy and mechanical engineering, Shanghai University of Electric Power, 200090 Shanghai, China
}

\begin{abstract}
The influence of pulverized coal particle size on combustion and NOx formation of $660 \mathrm{MW}$ tangential combustion ultra-supercritical boiler in a power plant was studied by using commercial software FLUENT. The average particle size of pulverized coal was set at $61 \mu \mathrm{m}, 71 \mu \mathrm{m}$ and $80 \mu \mathrm{m}$, respectively. The results show that with the decrease of pulverized coal particle size, the overall temperature level of the boiler increases, the average temperature of the main combustion zone increases, the temperature of the upper part of the main combustion zone decreases, and the combustion of pulverized coal is more incomplete. However, the probability of particles sticking to the wall and the probability of coking and slagging of the boiler increases. The amount of NOx produced in the main combustion zone decreases, while the amount of NOx produced in the upper part of the main combustion zone increases, while the overall amount of NOx produced increases slightly.
\end{abstract}

\section{Introduction}

Coal is internationally primary energy because of its large supply and low $\operatorname{cost}^{[1]}$. In the past 30 years, China has continued its coal based energy structure ${ }^{[2]}$. However, a large number of pollutants, such as smoke, SOx (sulfur oxides), $\mathrm{NOx}$ (nitrogen oxide) and $\mathrm{CO}_{2}$ (carbon dioxide), will be produced in the coal-fired power generation process $^{[3]}$. With the gradual improvement of environmental protection requirements, it has practical significance to improve the efficiency and reduce the pollution in the whole power generation process. In the process of boiler combustion, the properties of fuel will have a great impact on the combustion characteristics of the boiler.

Because of the complexity of boiler combustion, some combustion details are hard to be obtained by experimental method. In order to obtain the detailed data of the whole combustion process and reduce the cost, the numerical simulation can be used to study the boiler combustion and obtain the necessary data.

Many scholars have studied the combustion process of boilers with different sizes and different combustion modes by numerical simulation. Reynolds-averaged Navier-Stokes simulation (RANS) $)^{[4,5]}$, large-eddy simulation $(\mathrm{LES})^{[5-7]}$ and direct numerical simulation(DNS) ${ }^{[8,9]}$ were used to study coal combustion. The results show that reliable results can be obtained by numerical simulation.

Therefore, the purpose of this study is to obtain combustion details of the boiler combustion and to study how the size of pulverized coal particles affects boiler combustion.

\section{Materials and Methods}

\subsection{Boiler and fuel data}

The boiler used in this simulation is a vertical water wall supercritical DC boiler with single hearth, $\pi$ type arrangement and suspension structure. The burners are arranged on four corners, and tangential combustion is used. The furnace is $70151 \mathrm{~mm}$ high, $20336 \mathrm{~mm}$ wide and $19230 \mathrm{~mm}$ deep.

Table 1. Fuel data

\begin{tabular}{|c|c|c|c|}
\hline $\begin{array}{c}\text { Proximate } \\
\text { analysis } \\
\text { (as-received) }\end{array}$ & \%wt & $\begin{array}{c}\text { Ultimate } \\
\text { analysis } \\
\text { (dry-ash free) }\end{array}$ & \%wt \\
\hline $\mathrm{H}_{2} \mathrm{O}$ & 24 & $\mathrm{C}$ & 74.6 \\
\hline Volatiles & 22.6 & $\mathrm{H}$ & 3.7 \\
\hline Fixed carbon & 34.4 & $\mathrm{O}$ & 19.9 \\
\hline Ash & 19 & $\mathrm{~N}$ & 0.9 \\
\hline & & $\mathrm{S}$ & 0.9 \\
\hline
\end{tabular}

The burners adopt a large windbox structure with tangential combustion at four corner and full rotary burner. There are six layers in the horizontal primary air inlet, fifteen layers in the auxiliary air chamber and one layer in the burnout air chamber. The burners are installed at four corners. There are 6 layers of pulverized coal nozzle inside the burner. OFA nozzle is located above the burner, and there are six extra burnt-out air nozzles about 7.206 meters above the upper pulverized coal nozzle. The burners 
arrangement at the lower part of the furnace is shown in Figure 1. The upper burner and the lower combustion zone are similar in structure, except that the top layer of the upper burner is the OFA nozzle and the upper burner is 6 layers of SOFA nozzle.

Table 1 shows the detailed fuel data used in the simulation, which is mainly based on the received basis(as-received) and the dry ash free basis(dry-ash free).

\subsection{Grid division settings}

The boiler grid is structured, divided into regions, and divided by high-quality hexahedron grids. The total number of grids is $1.20 \times 10^{6}$. The overall grid division of the boiler is as shown in the Figure 1. In order to guarantee the accuracy of the simulation, the grid of the main combustion zone is encrypted. Quad grid and Pave grid are used to simulate the outlet cross-section of burner. Figure 2 shows the grid distribution at the outlet of burner.

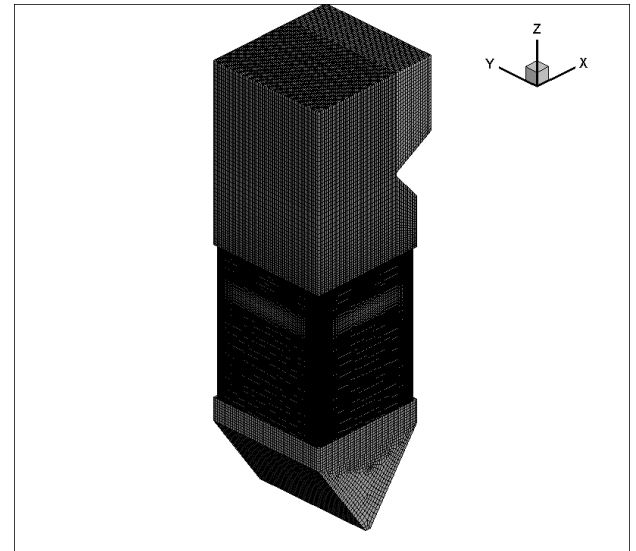

Fig1. Overall grid distribution of boiler.

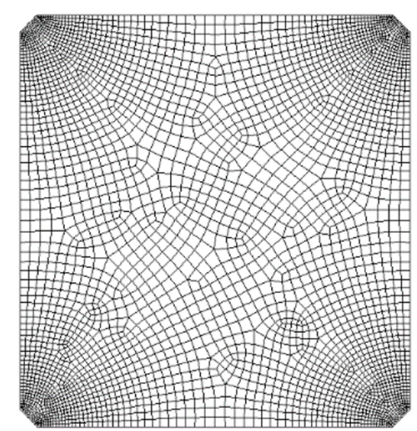

Fig2. Grid distribution at the outlet of burner.

\subsection{Calculation model settings}

In the numerical calculation, the standard k-epsilon twoequation model is used to calculate the gas turbulence, and the non-premixed combustion is used as the gas combustion model. Double equation parallel reaction model is used for coal pyrolysis, stochastic trajectory model is used for coal particle motion, kinetic/diffusion control reaction rate model is used for coke combustion, and $\mathrm{p} 1$ method is used for radiation heat transfer calculation.

\subsection{Pulverized coal particle size settings}

The particle size of pulverized coal particles is usually expressed by the fineness of pulverized coal $\left(R_{x}\right)$, and $R_{x}$ is the residual mass percentage of the total mass of the sieve with the mesh diameter of $x \mu \mathrm{m}$. China's coal-fired power plants use $90 \mu \mathrm{m}$ and $200 \mu \mathrm{m}$ sieves for screening, that is, $R_{90}$ and $R_{200}$ are used to represent the size of pulverized coal particles. The uniformity index of pulverized coal particles can be calculated by the following formula:

$$
n=\frac{\lg \left(\ln \frac{100}{R_{200}}-\ln \frac{100}{R_{90}}\right)}{\ln \left(\frac{200}{90}\right)}
$$

In FLUENT, the particle size of pulverized coal is determined by the maximum particle size, the minimum particle size and the mean particle size. In this simulation, the particle size of pulverized coal under three operating conditions is adopted, as shown in Table 2.

Table 2. Calculation condition settings

\begin{tabular}{|c|c|c|c|}
\hline $\begin{array}{c}\text { Working } \\
\text { condition }\end{array}$ & $\mathrm{R}_{90} / \%$ & $\mathrm{R}_{200} / \%$ & $\begin{array}{c}\text { Uniformity } \\
\text { index }\end{array}$ \\
\hline 1 & 21 & 2 & 1.15 \\
\hline 2 & 26 & 2.4 & 1.27 \\
\hline 3 & 31 & 2.8 & 1.39 \\
\hline
\end{tabular}

To calculate the fineness of pulverized coal with different particle sizes, $R_{x}$ can be calculated from $\mathrm{b}$ and $\mathrm{n}$ according to the Rosin-Rammler formula ${ }^{[3]}$, and the particle distribution of pulverized coal can be obtained. The Rosin-Rammler formula is as follows:

$$
R_{x}=e^{-b x^{n}}
$$

Where, $b$ is the coefficient representing the fineness of pulverized coal. $b$ can be obtained by the above formula and $R_{90}$, that is:

$$
b=\frac{1}{90^{n}} \ln \frac{100}{R_{90}}
$$

The fineness calculation of pulverized coal under different working conditions is shown in Table 3 . It can be seen from table 3 that the particle size distribution of pulverized coal is concentrated between $1 \mu \mathrm{m}$ and $250 \mu \mathrm{m}$ so the minimum and maximum particle sizes are set as $1 \mu \mathrm{m}$ and $250 \mu \mathrm{m}$.

$R_{x}$ can also be expressed by formula 4 . The average particle size of pulverized coal can be obtained when the particle size of pulverized coal is $x=x_{d}$, that is, $R_{x}=36.8$. The average particle size of working conditions 1 to 3 are $61 \mu \mathrm{m}, 71 \mu \mathrm{m}$ and $80 \mu \mathrm{m}$, respectively.

$$
R_{x}=e^{-\left(\frac{x}{x_{d}}\right)^{n}}
$$


Table 3. Particle size distribution of pulverized coal

\begin{tabular}{|c|c|c|c|}
\hline $\mathrm{R}_{\mathrm{x}} / \%$ & $\begin{array}{c}\text { Working } \\
\text { condition } 1\end{array}$ & $\begin{array}{c}\text { Working } \\
\text { condition } 2\end{array}$ & $\begin{array}{c}\text { Working } \\
\text { condition } 3\end{array}$ \\
\hline $\mathrm{R}_{1}$ & 99.1 & 99.6 & 99.8 \\
\hline $\mathrm{R}_{50}$ & 45.2 & 52.8 & 59.6 \\
\hline $\mathrm{R}_{100}$ & 17.2 & 21.4 & 25.8 \\
\hline $\mathrm{R}_{200}$ & 2.0 & 2.4 & 2.9 \\
\hline $\mathrm{R}_{250}$ & 0.6 & 0.7 & 0.8 \\
\hline
\end{tabular}

\section{Results \& Discussion}

\subsection{Influence of pulverized coal particle size on furnace temperature}
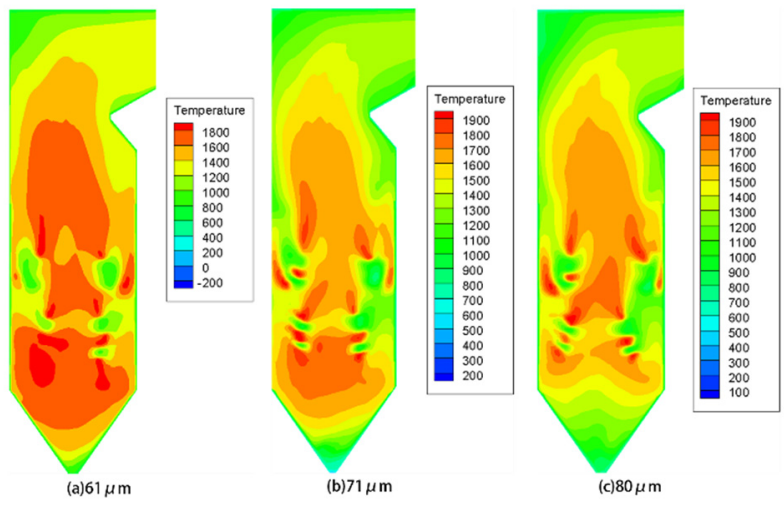

Fig3. Temperature distribution of furnace section $y=10.168 \mathrm{~m}$.

It can be seen from Figure 3 and Figure 4 that under the three working conditions, the overall average temperature of the furnace is arranged from large to small, with $61 \mu \mathrm{m}>$ $71 \mu \mathrm{m}>80 \mu \mathrm{m}$. With the decrease of pulverized coal particle size, the furnace temperature increases first, then decreases and finally increases. This is because in the main combustion zone and ash hopper zone of the furnace, the boiler with small particle size burns faster and more fully, which leads to the temperature rising with the decrease of particle size. In the upper part of the main combustion zone, because the boiler with small particle size burns more completely in the main combustion zone, the upper part of the main combustion zone burns less pulverized coal and the upper part of the main combustion zone has a lower temperature. In the top heat exchanger area, the overall temperature level is higher, because the boiler with smaller coal particle sizes burn more completely.

\subsection{Influence of pulverized coal particle size on formation of carbon dioxide}

It can be seen from Figure 5 that with the decrease of pulverized coal particle size, the overall $\mathrm{CO}_{2}$ generation increases. In the main combustion zone and the cold ash hopper zone, the amount of $\mathrm{CO}_{2}$ production increased significantly, while in the upper part of the main combustion zone, the amount of $\mathrm{CO}_{2}$ production decreased slightly. With the decrease of particle size of pulverized coal, the pulverized coal burns faster and more completely in the main combustion zone of the boiler, which leads to the increase of $\mathrm{CO}_{2}$ concentration in the main combustion zone and ash hopper zone. For boilers with large particle size of pulverized coal, part of pulverized coal burns out in the upper part of the main combustion zone, which leads to an increase in $\mathrm{CO}_{2}$ concentration.

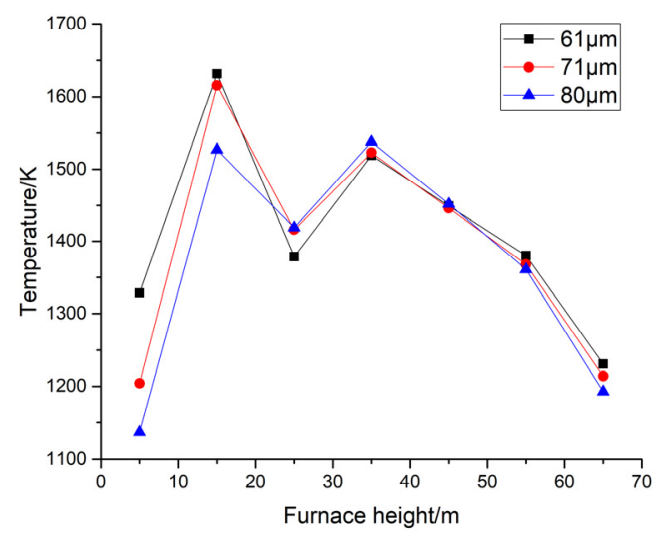

Fig4. Temperature distribution along furnace height.
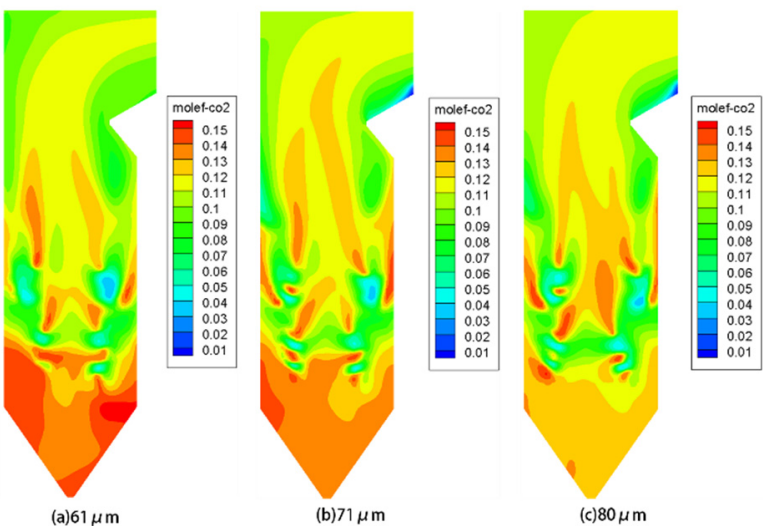

Fig5. $\mathrm{CO}_{2}$ distribution of furnace section $\mathrm{y}=10.168 \mathrm{~m}$.

\subsection{Influence of pulverized coal particle size on formation of nitrogen oxides}

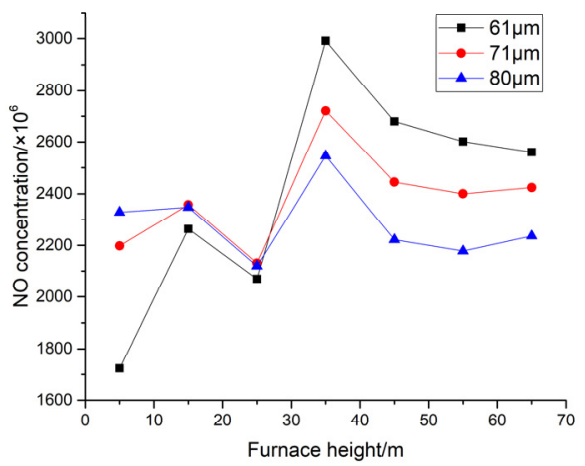

Fig6. Distribution of NO concentration along furnace height. 
It can be seen from Figure 6 that the distribution of nitric oxide concentration along the furnace height, the maximum value of nitric oxide concentration falls between $30 \mathrm{~m}$ and $40 \mathrm{~m}$, that is, the upper part of the main combustion area of the furnace. At the same time, the NO concentration is higher in the range of $40 \mathrm{~m} \sim 70 \mathrm{~m}$, which indicates that the NO in the boiler combustion process is mainly hot NO. On the one hand, the pulverized coal is still burning in the upper and top combustion zones of the main combustion zone, which provides enough temperature for the generation of NO; on the other hand, the combustion of pulverized coal is not so intense that it does not consume a lot of $\mathrm{O}_{2}$, thus providing sufficient $\mathrm{O}_{2}$ for NO generation.

With the decrease of pulverized coal particle size, the NO concentration produced by boiler combustion increases. When the furnace height is less than $30 \mathrm{~m}$, the NO concentration decreases with the decrease of particle size. This is because the smaller the particle size of pulverized coal, the more complete the combustion of pulverized coal in the main combustion zone, and the more $\mathrm{O}_{2}$ consumed, which leads to the lack of $\mathrm{O}_{2}$ needed for $\mathrm{NO}$ production, thus inhibiting the production of NO.

\subsection{Influence of pulverized coal particle size on coking and slagging of boiler}

Table 4. Granular state.

\begin{tabular}{|c|c|c|c|c|}
\hline $\begin{array}{c}\text { Working } \\
\text { condition }\end{array}$ & Tracked & Escaped & Trapped & Incomplete \\
\hline 1 & 11760 & 11313 & 413 & 34 \\
\hline 2 & 11760 & 11333 & 412 & 15 \\
\hline 3 & 11760 & 11375 & 373 & 12 \\
\hline
\end{tabular}

It can be seen from Table 4 that with the increase of the particle size of pulverized coal, the number of particles captured on the boiler wall decreases, and the number of incomplete combustion particles decreases. With the decrease of pulverized coal particle size, the overall temperature of boiler increases and the combustion process accelerates. When particles contact the wall, they are more likely to adhere to the wall, the residence time of particles is shortened, and the number of incomplete combustion particles increases. Under the same combustion conditions, the boiler with small pulverized coal particle size has a higher probability of particles sticking to the furnace wall and coking and slagging due to its higher temperature.

\section{Conclusions}

The results show that the decrease of pulverized coal particle size is beneficial to boiler combustion, and the disadvantages outweigh the advantages. The conclusions can be summarized into the following four parts:

With the decrease of pulverized coal particle size, the overall temperature level of the boiler increases, the average temperature near the main combustion zone increases, the temperature of the upper part of the main combustion zone decreases slightly, and the temperature of the top burner zone increases.

With the decrease of the particle size of pulverized coal, the combustion time of pulverized coal is advanced, the combustion speed of pulverized coal is faster and the combustion of pulverized coal is faster and more thorough. However, the probability of particles sticking to the wall and coking and slagging increases.

With the decrease of the particle size of pulverized coal, the total $\mathrm{CO}_{2}$ output increases. In the main combustion zone and the cold ash hopper zone, the amount of $\mathrm{CO}_{2}$ production increased significantly, while in the upper part of the main combustion zone, the amount of $\mathrm{CO}_{2}$ production decreased slightly.

With the decrease of pulverized coal particle size, the NOx produced by the whole boiler increases slightly, the NOx production near the main combustion zone decreases, and the NOx production in the upper part of the main combustion zone and the top area of the burner increases.

\section{References}

1. Z. Li, X. Liu, Y. Shao, W. Zhong. Research and Development of Supercritical Carbon Dioxide CoalFired Power Systems. J. Therm. Sci, 29:546575(2020).

2. J. Teng, Y. Qiao, P. Song. Analysis of coal demand, exploration potential and efficient utilization in China. Acta geophysics, 59: 4633-4653(2016).

3. A. Jiang, Q. Zhu. Environmental pollution of thermal power plants and its prevention and control progress. Power System Engineering, 13:1-4(1997).

4. R. Kurose, H. Watanabe, H. Makino. Numerical simulations of pulverized coal combustion. KONA Powder Particle J, 27:144-56(2009).

5. L. Chen, AF. Ghoniem. Simulation of oxy-coal combustion in a $100 \mathrm{~kW}$ th test facility using RANS and LES: avalidation study. Energy Fuels , 26:478398(2012).

6. BM. Franchetti, FC. Marincola, S. Navarro-Martinez, AM. Kempf. Large Eddy simulation of a pulverized coal jet flame. Proc Combust Inst, 34:2419-26(2013).

7. M. Rabacal, BM. Franchetti, FC. Marincola, F. Proch, M. Costa. Large Eddy Simulation of coal combustion in a large-scale laboratory furnace. ProcCombust Inst, 35:3609-17(2014).

8. T. Hara, M. Muto, T. Kitano, R. Kurose, S. Komori. Direct numerical simulation of a pulverized coal jet flame employing a global volatile matter reaction scheme based on detailed reaction mechanism. Combust Flame, 162:4391-407(2015).

9. M. Muto, K. Yuasa, R. Kurose. A DNS study on effect of coal particle swelling due to devolatilization on pulverized coal jet flame. Fuel, 184:749-52(2016). 